\title{
Analysis of written advertising material distributed through community pharmacies in Riyadh, Saudi Arabia
}

\author{
Sinaa AbdulMohsen AL-AQEEL, Jawza Fahad AL-SABHAN, Noha Yahia SULTAN.
} Received (first version): 7-May-2012 Accepted: 13-Sep-2013

\begin{abstract}
*
Background: Advertising is a crucial component of pharmaceutical industry promotion. Research indicates that information on advertisement materials might be inadequate, inaccurate, biased, and misleading.

Objective: To analyse and critically assess the information presented in print pharmaceutical advertisements in Saudi Arabia.

Methods: Pharmaceutical advertisements were collected from 280 community pharmacies in Riyadh city, Saudi Arabia. The advertisements were evaluated using criteria derived from the Saudi Food and Drug Authority (SFDA) regulation, the World Health Organization (WHO) ethical medicinal drug promotion criteria, and other principles reported in similar studies. The data were extracted independently by two of the researchers using a standardized assessment form.

Results: One hundred eighty five printed advertisements were included in the final sample. Approximately half of the advertisements $(n=94$, $51 \%$ ) were for over-the-counter (OTC) medications, and $71(38 \%)$ were for prescription-only medication. Information such as the name of active ingredients was available in 168 (90.8\%) advertisements, therapeutic uses were mentioned in 156 (98.7\%) of analysed advertisements. Safety information related to side effects, precautions, and major interactions were stated in $53(28.5 \%), 58(31 \%)$, and 33 (16.5\%) advertisements, respectively. Only 119 advertisements (64\%) provided references for information presented.

Conclusions: Our findings suggest that print advertisements do not convey all the information necessary for safe prescribing. These results have implications for the regulation of drug advertising and the continuing education of pharmacists.
\end{abstract}

Keywords: Advertising as Topic; Drug Industry; Pharmacies; Pharmacists; Saudi Arabia

\footnotetext{
*'Sinaa AbduIMohsen AL-AQEEL. Department of Clinical Pharmacy, College of Pharmacy, King Saud University. Riyadh (Saudi Arabia). salageel@ksu.edu.sa Jawza Fahad AL-SABHAN. Department of Clinical Pharmacy, College of Pharmacy, King Saud University. Riyadh (Saudi Arabia).

Noha Yahia SULTAN. Department of Clinical Pharmacy, College of Pharmacy, King Saud University. Riyadh (Saud Arabia).
}

\author{
ANÁLISIS DEL MATERIAL ESCRITO DE \\ PROPAGANDA DISTRIBUIDO A TRAVÉS \\ DE FARMACIAS COMUNITARIAS EN \\ RIYADH, ARABIA SAUDITA
}

\section{RESUMEN}

Antecedentes: La propaganda es un componente crucial de la promoción de la industria farmacéutica. La investigación indica que la información de los materiales de propaganda puede ser inadecuada, imprecisa, sesgada y engañosa. Objetivo: Analizar y evaluar críticamente la información presentada en los anuncios impresos en Arabia Saudita.

Métodos: Se recogió propaganda farmacéutica de 280 farmacias comunitarias en la ciudad de Riyadh, Arabia Saudita. Los anuncios fueron evaluados usando los criterios derivados de la reglamentación de la Autoridad Saudita de Medicamentos y Alimentos (SFDA), y de los criterios éticos de promoción de productos medicinales de la Organización Mundial de la Salud (OMS). Los datos fueron extraídos independientemente por dos de los investigadores utilizando un formulario de evaluación estandarizado.

Resultados: Se incluyeron en la muestra final 185 anuncios escritos. Aproximadamente la mitad de los anuncios ( $\mathrm{n}=94 ; 51 \%)$ eran de medicamentos OTC y 71 (38\%) eran de medicamentos de prescripción. Información tal como nombre de los principios activos estaba disponible en 168 (90,8\%) de los anuncios, usos terapéuticos aparecían en 156 (98,7\%). Información sobre la seguridad relacionada con los efectos secundarios, precauciones e interacciones serias estaba presente en 53 (28.5\%), 58 (31\%), y 33 (16.5\%) anuncios, respectivamente. Sólo 119 anuncios (64\%) proporcionaban referencias para la información presentada.

Conclusiones: Nuestro hallazgos sugieren que los anuncios escritos no contienen toda la información necesaria para una prescripción segura. Estos resultados tienen implicaciones para la reglamentación de la propaganda de medicamentos y la formación continuada de los farmacéuticos.

Palabras clave: Publicidad como Asunto; Industria Farmacéutica; Farmacias; Farmacéuticos; Arabia Saudita 


\section{INTRODUCTION}

The World Health Organization (WHO) defines drug promotion as "all informational and persuasive activities by manufacturers and distributors, the effect of which is to induce the prescription, supply, purchase and/or use of medicinal drugs". It is estimated that the pharmaceutical industry spent over USD23 million on pharmaceutical promotion to providers such as free samples, journal advertisements and conferences in the United State alone in $2010^{2}$

Physicians may use advertisements as one of the sources of information for newly marketed drugs. ${ }^{3,4}$ Research also indicates that information in advertising materials may influence the prescribing behaviour of the physicians. ${ }^{4,5}$ A recent systematic review $^{5}$ examined the relationship between exposure to information directly provided by pharmaceutical companies and the quality, quantity, and cost of physicians' prescribing. The review included 58 studies, and the findings suggest that exposure to information may result in higher prescribing frequency of advertised drugs and higher costs. ${ }^{5}$ Another review also found a link between pharmaceutical promotion and increased requests by physicians for adding drugs to the hospital formulary and changes in prescribing practice. $^{6}$

The WHO criteria for ethical medicinal drug promotion indicate that advertisements to physicians and related health professionals should contain certain information. ${ }^{1}$ The WHO recommend that advertisement should contain an approved generic name; the brand name; content of active ingredients per dosage form; name of other ingredients known to cause problems; approved therapeutic uses; dosage form or regimen; side effects and major adverse reactions; precautions, contraindications, and warnings; the name and address of manufacturer or distributor; and references to scientific literature. Other governmental regulations of drug-promotion activities also available in many parts of the world. ${ }^{6-8}$ Despite that, previous research examined advertisements in medical journals or advertisements circulated by pharmaceutical representatives through physicians' clinics and community pharmacies found that information in advertisement materials might be inadequate, inaccurate, biased, and misleading. ${ }^{7-16}$ For instance, the findings of these studies indicated low rates of reporting safety information, like interaction, contraindications, and precautions.

The Saudi Food and Drug Authority (SFDA) is responsible for developing and enforcing the regulatory system for the pharmaceutical sector in Saudi Arabia. The advertisement materials should first be reviewed and approved by the SFDA. The regulation on the dissemination of drug advertising materials in Saudi Arabia was updated by the SFDA in 2011. ${ }^{17}$ It states that advertisement is only allowed for registered products with few exceptions for advertising unregistered innovative or new drugs at scientific conferences. Legally, advertising of prescription-only drugs is limited to scientific journals, scientific conferences, and specialised meetings. The guidelines require that advertisements should not include misleading information or phrases that might be misinterpreted. The regulations, however, does not explain what constitutes misleading information. The regulations go further to require that the advertising material should not include any statement that negatively affects other products.

To our knowledge, there is no analytical survey of the quality of pharmaceutical advertising in Saudi Arabia. Of particular concern are advertised materials distributed to community pharmacists. Research suggests that self-medication is common in Saudi Arabia ${ }^{18}$, as well as purchasing legally prescription-only medications such as antibiotics without a prescription. ${ }^{19}$ In this context, community pharmacists could be the only healthcare care professional making recommendation and counselling for many patients. If community pharmacists acquire knowledge about benefits and risks of treatment from inadequate and misleading drug advertisements, it can be anticipated that his would lead to improper recommendations and counselling.

Therefore, the purpose of this study was to analyse and critically assess the information presented in print pharmaceutical advertisements in Saudi Arabia.

\section{METHODS}

\section{Data collection}

Pharmaceutical advertisements, which were circulated by pharmaceutical representatives, were collected from community pharmacies in Riyadh, Saudi Arabia. The advertisements were collected from a convenient sample of 280 community pharmacies from different parts of Riyadh. We stratified Riyadh city by geographical areas: north, south, west, east and central and ensured that advertisements were collected from different pharmacies in these areas. The advertisement were collected during different days of the week at different times of the day. The advertising materials were collected by fourth-year pharmacy students in the period between March 2011 and October 2011. The participation of students was voluntary. The students' role was to ask community pharmacists if they have any advertisement brochures and if the answer was yes to ask pharmacists to give them some of these brochures.

\section{Inclusion and exclusion criteria}

Advertising materials for hair-colouring dyes, baby lotion, baby formula, medical devices, and diagnostic equipment were excluded. The advertisements had to be complete and intact to be included. Duplicate advertisements were excluded. An advertisement was considered a duplicate if it is identical to previous ones in all respects (i.e. had the same name of the product, manufacture, design, and content). 


\begin{tabular}{|l|c|c|}
\hline \multicolumn{1}{|c|}{ Class } & $\mathrm{N}$ & $\%$ \\
\hline Rable 1. Indications for herbal products advertised $(\mathrm{n}=50)$ \\
\hline Respiratory problem (e.g. cough preparations) & 7 & 14 \\
\hline Sexual dysfunction & 5 & 10 \\
\hline Skin problems (e.g. acne) & 3 & 6 \\
\hline Pain (e.g. period pain) & 3 & 6 \\
\hline Musco-skeletal and joint pain & 3 & 6 \\
\hline Weight reduction & 3 & 6 \\
\hline Miscellaneous & 26 & 52 \\
\hline
\end{tabular}

\section{Content analysis}

An assessment form comprising a list of information that should be included in advertisements was designed. The list was derived from the SFDA regulation, the WHO ethical medicinal drug promotion criteria, and other principles reported in similar studies. We first obtained information on the registration of advertised product and its prescription status. The registration of the advertised products was verified by information recorded in two databases for registered drugs and herbal products available on the SFDA website ${ }^{20,21}$ which provide many information including the registration number of registered products. The legal prescription status for each medication as over the counter (OTC) or prescription only was also verified from the same two databases.

We then examined the report of information about the underlying disease condition such as prevalence rate and associated risk factors. We also screened advertisements for information reported about the advertised product such a success rate, side effects, precautions, and reference to any competing treatment. In order to examine if the advertising material include any statement that negatively affects other products, we searched the advertisement for statements such as "product $X$ is safer than product $Y$ " or "product $X$ is more potent than product $Y$ ".

We also examined use of references to support claims in analysed advertisements. References were classified as journal article, generic data on file (a reference to an unspecified, unpublished company document), book, and others (e.g. meeting abstract or presentation).

The data were extracted by two of the researchers (JS and NS) using the assessment form independently. Where there was a disagreement, the opinion of the third researcher (SA) prevailed. However, there was a substantial agreement between JS and NS and disagreements happened three or four times only.

\section{Data analysis}

Data were entered into Excel. The number of advertisement materials which met the quality criteria was calculated. The results were expressed as absolute numbers and percentages.

\section{RESULTS}

Five hundred fifty-one advertisements were collected. Two hundred forty-six were excluded because they were promoting medical devices, haircolouring dyes, baby lotion, baby formula, or were incomplete advertisements. One hundred twenty were excluded because they were duplicates. Therefore, 185 printed advertisements were included in the final sample.

\section{Advertisement characteristics}

Fifty advertisements (27\%) were for herbal products (Table 1). The therapeutic classes for the remaining $135(73 \%)$ advertisements promoting medications were categorised according to the British National Formulary (BNF) classification and presented in Table 2.

The advertised product represents 60 pharmaceutical companies including Saudi 17 (28\%) and non-Saudi 43 (72\%) manufacturers. The multinational manufacturers located in Saudi Arabia were classified as non-Saudi manufacturers.One local Saudi pharmaceutical company contributed to $32(53 \%)$ of the advertising materials. Only 29 (15.7\%) advertisements have Arabic translation to the promotional contents.

Less than half $(n=82,44.3 \%)$ of the analysed advertisements used scientific charts to clarify their claims. On average, there were three charts per advertisement $(\min =1, \max =24)$. The most common chart type was a bar chart alone ( $n=50,61 \%)$, bar and line graph $(\mathrm{n}=14,17 \%)$, and bar and pie chart $(n=10,12 \%)$. Forty-four advertisements (54\%) depicted total sample size information with charts, albeit only 16 provided a sample size for each group. The $p$-value was presented with charts in 22 advertisements.

\section{Advertisement content analysis}

One hundred sixty five (89.0\%) of analyzed advertisements promoted products that were able to find registered in the SFDA databases. Approximately half of the advertisements $(n=94$, $51.0 \%$ were for over-the-counter (OTC) medications and $71(38.0 \%)$ were for prescriptiononly medication. The legal prescription status for 20

\begin{tabular}{|l|c|c|}
\hline \multicolumn{1}{|c|}{ Table 2. Therapeutic classes for medications advertised ( $\mathrm{n}=135)$} & Number \\
\hline \multicolumn{1}{|c|}{ Therapeutic class } & 25 & 19 \\
\hline Anti-microbial, anti-fungal, anti-viral & 19 & 14 \\
\hline Cardiovascular system medications & 16 & 12 \\
\hline NSAID and other analgesics & 16 & 12 \\
\hline Respiratory system medications & 12 & 9 \\
\hline Nutrition and blood medications & 11 & 8 \\
\hline Gastro-intestinal system medications & 36 & 27 \\
\hline Miscellaneous* & \multicolumn{2}{|}{} \\
\hline $\begin{array}{l}\text { NSAID: Non-Steroidal Anti-Inflammatory Drugs } \\
\text { *Anti-haemorrhoid drugs, musco-skeletal and joint medications, glucocorticoids, diabetic neuropathy drugs, } \\
\text { erectile dysfunction medications, teething baby gel, eye medications, skin medications, ear medications }\end{array}$
\end{tabular}




\begin{tabular}{|c|c|c|}
\hline Type of information & Number & $\%$ \\
\hline \multicolumn{3}{|l|}{ Information about the condition } \\
\hline 1. Name of condition treated by the promoted drug. & 182 & 98.4 \\
\hline 2. $\quad$ Condition associated risk factor & 31 & 16.8 \\
\hline 3. Condition prevalence rate & 31 & 16.8 \\
\hline \multicolumn{3}{|l|}{ Information about the advertised product } \\
\hline $\begin{array}{l}\text { 4. The name(s) of the active ingredient(s) using either INN or the approved generic name } \\
\text { of the drug }\end{array}$ & 168 & 90.8 \\
\hline 5. The brand name & 185 & 100.0 \\
\hline 6. Content of active ingredient(s) per dosage form or regimen & 147 & 79.5 \\
\hline 7. Name of other ingredients known to cause problems & 10 & 05.4 \\
\hline 8. Mechanism of action of the drug & 123 & 66.5 \\
\hline 9. $\quad$ Approved therapeutic uses & 182 & 98.4 \\
\hline 10. Dosage form or regimen & 183 & 98.9 \\
\hline 11. Expected time of onset of action & 26 & 14.1 \\
\hline 12. Success estimate of treatment & 84 & 45.4 \\
\hline 13. Side-effects and major adverse drug reactions & 53 & 28.6 \\
\hline 14. Precautions, contra-indications, and warnings & 58 & 31.4 \\
\hline 15. Major interactions & 33 & 17.8 \\
\hline 16. Comparison with competing treatment & 57 & 30.8 \\
\hline 17. Name and address of manufacturer or distributor & 175 & 94.6 \\
\hline 18. Reference to scientific literature & 119 & 64.3 \\
\hline
\end{tabular}

(11\%) advertisements could not be determined, as they were not registered in any of the databases searched.

Table 3 presents information reported in analysed advertisements. The underlying disease condition prevalence rate and risk factors were reported in 31 advertisements (16.8\%). Eighty-four advertisements (45.4\%) quantified the benefit and success rate. Information such as the names of active ingredients was available in 168 (90.8\%) advertisements, and therapeutic uses were mentioned in 183 (98.8\%) analysed advertisements (Table 2). Safety information related to side effects, precautions, and major interactions were stated in $53(28.6 \%), 58$ (31.4\%), and 33 (17.8\%) advertisements, respectively. Fifty-seven advertisements (30.8\%) compared their products to a competing treatment by stating the advantages of their product over the competing treatment.

Only 119 advertisements (64.3\%) provided references for information presented. In 111 advertisements $(60.0 \%)$, claims were supported by evidence from published journal articles with an average of six journal articles per advertisement $(\min =1, \max =19)$. Other references were data on file $(17 ; 9.2 \%)$, websites $(15 ; 8.1 \%)$, books (4; $2.2 \%)$, guidelines $(2 ; 1.1 \%)$, and meeting abstract or presentation $(22 ; 11.9 \%)$.

\section{DISCUSSION}

This study was an attempt to evaluate the drug advertisements distributed through community pharmacies. Our findings indicate that safety information related to side effects, precautions, and major interactions was inadequately reported in examined advertising materials.

Only $16 \%$ of the advertisements translated the promotional contents into Arabic, which suggested that the advertisements target healthcare professionals rather than the public. This is similar to a finding obtained in a study from a neighbouring country, the United Arab Emirates. ${ }^{15}$

Information on side effects and precautions is vital for patient counselling and patient care while information on contraindications is essential for minimising potential interactions that can be fatal in some instance or cause therapeutic failure. Our findings indicate that information on adverse effects, contraindications, and precautions was often missing. This finding is in concordance with previous research on advertisements circulated by pharmaceutical representatives through physicians' clinics and community pharmacies. Over $50 \%$ of analysed advertisements from Brazil $(n=827)$ failed to mention the main contraindications. ${ }^{13}$ An Indian study found that only 45 out of $513(9 \%)$ advertising materials mentioned the safety information. ${ }^{14}$ Another study of 67 advertisements in Dubai found that safety information, like interaction, contraindications, and precautions, were lacking in $21 \%, 12 \%$, and $47 \%$ respectively. ${ }^{15}$ In a study which examined 110 advertisements in Zimbabwe, adverse reactions and precautions were missing in more than $50 \% .{ }^{16}$ Similar findings are also common in studies examining advertisements in medical journals. Othman et al. conducted a systematic review on studies that examined the quality of pharmaceutical advertisements in medical journals. ${ }^{7}$ The review identified 24 studies from Europe, the United States, and other countries. Five studies recorded information on side-effects reporting in journal advertisements and found low rates of reporting - around $14 \%$ or less (median=6\%). Six studies examined information on contraindications, warnings, precautions available in journal advertisements and found the rate of reporting to be less than $74 \%$ (median=35\%), 80\%-95\% (median=85\%), and 65\% (median=32\%) respectively. $^{7}$

In the present study, more than half of the advertisements supported their efficacy claims with journal articles; this is similar to findings from other studies. ${ }^{8,14,16}$ However, we noticed the poor 
referencing methods used as many omitted journal names, articles titles, publication years, or page numbers. This means that community pharmacists will not be able to trace and examine original references. We did not critically appraise the quality of studies used to support advertisement claims. This requires further research, specifically, that previous research indicates the frequent use of poor quality evidence to support claims of products efficacy. ${ }^{22-25}$

The majority of graphs used in analaysed advertisement are simple univariate displays which are easy to understand; however, Cooper et al. warn that such simple graphical displays may fail to convey the complexity of data and may distort the findings. ${ }^{26}$ The current study did not evaluate the accuracy of information reported in text or graphs used in the analysed advertisements. The accuracy of information presented in advertisements have been criticised in many studies..$^{8,9,10,22}$ Further investigation into this very important aspect of advertisement is a research priority.

Our findings underscore the need for more stringent guidelines for advertising In Saudi Arabia to minimise potential risk to the public. The SFDA needs to enforce these guidelines in a consistent, rigorous fashion and more importantly monitor adherence to these guidelines. The guidelines should clearly require that advertisements present information essential for appropriate prescribing such as clear risk quantification, absolute benefit information, description of the appropriate population to receive the drug, and verifiable references.

This study had several limitations. The sample size is small. Because advertising materials were collected from only selected community pharmacies in one city, these findings may not be generalised to other settings (i.e. physicians' clinics) or geographic regions. There may be seasonal variations in drug marketing that further limit generalisability, although this is unlikely given the wide range of drugs included in the study. Only advertisements circulated by the pharmaceutical representatives were examined; therefore, our findings may not be generalised to other types of promotional activities, such as journal advertisements.

\section{CONCLUSIONS}

Our findings suggest that print advertisements do not convey all information necessary for safe prescribing. These results have implications for the regulation of drug advertising and the continuing education of community pharmacists.

\section{ACKNOWLEDGEMENTS}

The author also thanks the Research Center of the Center for Female Scientific and Medical Colleges, King Saud University, for their financial support towards the publication of this paper.

\section{CONFLICT OF INTEREST}

All authors declare that they have no competing interests.

Funding sources: This research project was supported by a grant from the Research Center of the Center for Female Scientific and Medical Colleges, Deanship of Scientific Research, King Saud University.

\section{References}

1. World Health Organization. Ethical criteria for medicinal drug promotion. http://www.who.int/medicinedocs/collect/edmweb/pdf/wozip08e/whozip08e.pdf (Accessed May 7, 2012).

2. Gagnon MA, Lexchin J. The cost of pushing pills: A new estimate of pharmaceutical promotion expenditures in the United States. PLoS Med. 2008;5(1):e1. doi: 10.1371/journal.pmed.0050001

3. Vancelik S, Beyhun NE, Acemoglu $\mathrm{H}$, Calikoglu O. Impact of pharmaceutical promotion on prescribing decisions of general practitioners in Eastern Turkey. BMC Public Health. 2007;7:122.

4. McGettigan P, Golden J, Fryer J, Chan R, Feely J. Prescribers prefer people: The sources of information used by doctors for prescribing suggest that the medium is more important than the message. $\mathrm{Br} \mathrm{J}$ Clin Pharmacol. 2001;51(2):184-189.

5. Spurling GK, Mansfield PR, Montgomery BD, Lexchin J, Doust J, Othman N, Vitry Al. Information from pharmaceutical companies and the quality, quantity, and cost of physicians' prescribing: a systematic review. PLoS Med. 2010;7(10):e1000352. doi: 10.1371/journal.pmed.1000352

6. Wazana A. Physicians and the pharmaceutical industry: Is a gift ever just a gift? JAMA. 2000;283(3):373-380.

7. Othman N, Vitry AI, Roughead EE. Quality of claims, references and the presentation of risk results in medical journal advertising: a comparative study in Australia, Malaysia and the United States. BMC Public Health. 2010;10:294. doi: 10.1186/1471-2458-10-294.

8. Othman N, Vitry A, Roughead EE. Quality of pharmaceutical advertisements in medical journals: a systematic review. PLoS One. 2009;4(7):e6350. doi: 10.1371/journal.pone.0006350

9. Korenstein D, Keyhani S, Mendelson A, Ross JS. Adherence of pharmaceutical advertisements in medical journals to FDA guidelines and content for safe prescribing. PLoS One. 2011;6(8):e23336. doi: 10.1371/journal.pone.0023336

10. Montgomery BD, Mansfield PR, Spurling GK, Ward AM. Do advertisements for antihypertensive drugs in Australia promote quality prescribing? A cross-sectional study. BMC Public Health. 2008;8:167. doi: 10.1186/1471-2458-8-167

11. Tuffs A. Only $6 \%$ of drug advertising material is supported by evidence. BMJ. 2004;328(7438):485.

12. Rohra DK, Gilani AH, Memon IK, Perven G, Khan MT, Zafar H, Kumar R. Critical evaluation of the claims made by pharmaceutical companies in drug promotional material in Pakistan. J Pharm Pharm Sci. 2006;9(1):50-59. 
13. Wzorek LF, Copper CJ, Trindade AC, Pontarolo R. Analysis of medicine advertisement produced in Brazil. Pharm Pract. 2007;5(3):105-108.

14. Mali SN, Dudhgaonkar S, Bachewar NP. Evaluation of rationality of promotional drug literature using World Health Organization guidelines. Indian J Pharmacol. 2010;42(5):267-72. doi: 10.4103/0253-7613.70020

15. Sharif SI, Abduelkarem AR. Analysis of written pharmaceutical advertisement in Dubai \& Sharjah. Saudi Pharm J. 2008;16(34):252-257.

16. Sibanda N, Gavaza P, Maponga CC, Mugore L. Pharmaceutical manufacturers' compliance with drug advertisement regulations in Zimbabwe. Am J Health Syst Pharm. 2004;61(24):2678-2681.

17. The Saudi Food and Drug Authority-Drug sector- Licensing directorate. Guidance and Requirements Directory of Licensing Pharmaceutical and Herbal Product Advertising. http://www.sfda.gov.sa/En/Drug/Topics/Regulations++Guidelines.htm (Accessed May 7, 2012).

18. Alghanim SA. Self-medication practice among patients in a public health care system. East Mediterr Health J. 2011;17(5):409-416.

19. Bin Abdulhak AA, Altannir MA, Almansor MA, Almohaya MS, Onazi AS, Marei MA, Aldossary OF, Obeidat SA, Obeidat MA, Riaz MS, Tleyjeh IM. Non prescribed sale of antibiotics in Riyadh, Saudi Arabia: a cross sectional study. BMC Public Health. 2011;11:538. doi: 10.1186/1471-2458-11-538

20. The Saudi Food and Drug Authority. Registered Drugs List. http://www.sfda.gov.sa/En/D.htm (Accessed May 7, 2012).

21. Registered Herbal and Health Products List. The Saudi Food and Drug Authority. http://www.sfda.gov.sa/En/D.htm (Accessed May 7, 2012).

22. Rohra DK, Bashir MU, Khwaja UA, Nazir MR. Critical appraisal of apparently evidence-based written advertising in Pakistan. Pharm World Sci. 2008;30(3):216-221.

23. Cardarelli R, Licciardone JC, Taylor LG. A cross-sectional evidence-based review of pharmaceutical promotional marketing brochures and their underlying studies: is what they tell us important and true? BMC Fam Pract. 2006;7:13.

24. Heimans L, van Hylckama Vlieg A, Dekker FW. Are claims of advertisements in medical journals supported by RCTs? Neth J Med. 2010;68(1):46-49.

25. Cooper RJ, Schriger DL. The availability of references and the sponsorship of original research cited in pharmaceutical advertisements. CMAJ. 2005;172(4):487-491.

26. Cooper RJ, Schriger DL, Wallace RC, Mikulich VJ, Wilkes MS. The quantity and quality of scientific graphs in pharmaceutical advertisements. J Gen Intern Med. 2003;18(4):294-297. 